\title{
Lightning Disaster Risk Identification and Risk Management Measures
}

\author{
Jun Wang, Hailing Ma, Zhifeng Huang, Xiuying Wang*, Xiaoyan Liu, Jihong Zhang, \\ Xinjian Zhu
}

Qinghai Meteorological Disaster Prevention Technology Center, Xining 810001, China

\section{雷电灾害风险识别与风险管理措施}

王军, 马海玲, 黄志凤, 王秀英*, 刘晓燕, 张继红, 朱新健

青海省气象灾害防御技术中心, 西宁 810001 , 中国

\begin{abstract}
The risk identification of lightning disaster is the work of discovering and identifying the risk of lightning disaster in the system. This is a very important work, which is the basis of risk control and management of lightning disaster and can help to think purposefully about how to take action to control risk. Risk management generally refers to the whole process of identifying, evaluating and judging risks, and making decisions and taking actions to reduce consequences and monitor feedback. At present, the thunder and lightning disasters emergency risk management is still in its infancy, the accident emergency risk management research, mostly concentrated in the organizations or enterprises subject level, the lack of risk management from the perspective of public management research. This paper takes the accident of lightning strike accident at xingye primary school, kaixian county, chongqing and lightning disaster in yushu earthquake area of qinghai province as an example to study the existing
\end{abstract}

*通讯作者: 王秀英 (1987-), 女, 工程师, 硕 士, 研究方向: 气象灾害防御; 邮箱:

12630374@qq.com problems in the risk management of lightning disaster in China are to put forward the measures for the risk management of lightning disaster.

Keywords: Lightning disaster; Risk identification; Management measures.

摘要

雷电灾害风险识别是发现、识别系统中 雷电灾害风险的工作。这是一件非常重要的 工作, 它是雷电灾害风险控制和管理的基 础, 只有识别了风险之后才能有的放矢地考 虑如何采取措施控制风险。而风险管理一般 是指识别、评估和判断风险, 并进行决策、 采取行动以减少后果及监控反馈的全过程。 目前我国雷电灾害突发事件风险管理还处 于初级阶段, 对于事故突发事件风险管理研 究, 大多集中在团体或企业主体层面, 缺乏 从公共管理视角开展风险管理研究。本文以 重庆开县兴业小学雷击事故、青海玉树地震 灾区雷电灾害为例，探讨我国雷灾事故风险 管理存在的问题, 提出雷电灾害风险管理的 措施。

关键词: 雷电灾害; 风险识别; 管理措施

1. 引言

雷电灾害风险管理是雷电灾害突发事 件预防工作的核心, 也是各级政府和气象部 
门获得准确预警信息的重要途径。目前, 许 多学者从旅游、建筑、化工等团体或企业主 体角度提出适用于不同行业的雷电灾害风 险管理模式, 开展雷电事故可能性、事故预 测模型、预警、风险值等方面的技术研究。 然而, 从公共管理视角进行的雷电灾害风险 管理研究在我国还很欠缺。因此, 在公共管 理视角下, 针对雷电灾害事故突发事件的特 点进行风险管理研究, 建立和完善雷电灾害 事故突发事件风险管理体系, 对预防、减少 和消除雷电灾害突发事件具有一定的紧迫 性和现实意义。

\section{2. 雷电灾害事故风险管理的特殊性}

雷电灾害事故突发事件风险管理包括 识别和分析与工作相关的安全和健康的危 险源; 识别危险源导致的各种次生灾害风险 尤其是对周围环境的影响; 提出控制和减少 雷电灾害风险的措施; 将所有识别到的雷电 灾害风险通知到所有可能受影响的人群等。 相对于其他类突发事件, 它有自己的特殊 性。

一是雷电灾害风险管理责任主体具有 特殊性。雷电灾害事故突发事件风险管理涉 及企业和政府几大责任主体, 这有别于其他 种类尤其是自然灾害突发事件风险管理。由 于雷电灾害风险源往往存在于团体活动、企 业生产、经营和使用过程中, 故而雷电灾害 风险管理责任主体在团体或企业, 监管责任 主体在政府或行政管理机构。

二是雷电灾害风险源排查工作性质特 殊。自然灾害的危险源被称为致灾因子, 危 险源比较单一容易识别。而雷电灾害的危险 源往往不是单一出现的, 较为复杂的情况则 是几种风险源叠加或交替出现, 比如暴雨、 洪涝、地震等。例如, 2010 年 4 月 14 日玉 树发生的地震, 地震期间正值雷电活动高峰 期, 地震灾后面临着防雷设施破坏、临时避 难场所防雷设施不完善等问题, 导致地震灾 后雷电灾害事件的叠加。地震的致灾因子往 往被称为天灾, 很难避免。而雷电灾害事故 的风险源一般存在于团体的活动、企业的生 产、使用、经营及老百姓生活过程中, 被叫 做人祸, 比如由雷电引起的烟花爆竹爆炸、 危化品爆炸、人员伤亡和财产损失等, 如果
雷电风险源被及时识别, 那么所谓的人祸完 全可以避免或者减轻。另外, 因为雷电灾害 风险源种类众多、繁杂且不易识别, 所以各 级安全监督管理部门应把雷电灾害事故风 险源排查的监督管理作为首要工作。

三是雷电灾害风险管理重点在于雷电 灾害风险源对周边环境的影响评估。雷电灾 害事故风险管理的重点不仅是雷电灾害风 险识别及风险源排查, 更在于风险源对周边 环境的影响评估。例如某化工厂一旦发生因 雷电灾害造成危化品爆炸, 会对周边人口、 空气、环境、住宅等产生各种影响, 化工厂 应当意识到这种影响并进行影响评估。雷电 灾害风险源对环境的影响评估意义重大, 是 雷电灾害事故突发事件风险管理的重点。

\section{3. 对于相关雷电灾害事故突发事件风险 管理存在问题的反思}

\section{1 “5.23” 兴业小学雷击事故案例分析}

2007 年 5 月 23 日重庆开县义和镇兴业 小学遭受雷击, 造成 7 名小学生死亡、44 名 小学生受伤。根据重庆市气象局调查基本查 明, 伤亡事故发生的主要原因是, 当雷电击 中教室金属窗时, 由于金属窗未作接地处 理, 雷电流无处泄放, 靠近窗户的学生就成 了雷电流泄放入地的通道, 雷电流的热效应 导致学生出现伤亡。

\section{2 雷电灾害事故突发事件风险管理存在 的问题}

由于雷电灾害相对于其他灾害属于小 概率事件, 尽管发生后所造成的人员伤亡和 财产损失较大, 但还是经常不被人们所重 视。因此, 在各行业各领域均存在雷电灾害 事故风险管理体系不健全、不完善、不到位 现象, 使得对雷电灾害风险的识别缺失、评 估不全面、判断不准确, 导致不能采取有 效的雷电防御措施, 无法避免或减轻雷电灾 害所造成的人员伤亡和经济损失。

\section{3 加强雷电灾害事故突发事件风险管理 的建议}

3.3.1 要充分认识雷电灾害事故突发事件风 险管理工作的重要性

随着现代化城市的迅速发展, 城市高层 建筑物尤其是人员密集的公共建筑日趋增 
多, 信息技术设备日益增加, 雷电灾害事故 突发事件风险管理工作已经成为雷电灾害 防御工作的重中之重。通过这些年频发的雷 击事故, 从风险管理的角度不得不引起我们 的思考。

3.3.2 如何做好雷电灾害事故突发事件风险 管理工作

一是要开展全方位、多角度、有针对性 的雷电灾害风险识别; 二是根据所识别雷电 灾害风险, 进行分类或分区评估, 判断危险 源; 三是建立雷电灾害事故突发事件风险管 理体系, 该体系包括: 雷电灾害的普查、雷 电灾害风险的识别、雷电灾害风险原的分 析、雷电灾害风险环境影响的评估、雷电灾 害防御措施的指导性文件、防雷减灾科普知 识的宣传等。

\subsection{3 严格落实安全责任考核制度}

各级人民政府应当将雷电灾害事故突 发事件风险管理工作作为安全生产工作的 重要内容, 并将此项工作纳入政府对安全生 产第一责任人、直接责任人的年度考核范 围, 同时加大对安全生产第一责任人和直接 责任人的考核工作力度。相关部门通过联合 检查、联合执法的形式, 依据相关法律法规, 严肃查处违反雷电灾害风险管理规定的行 为。因违反规定, 导致雷击事故或应急处置 不力造成重大损失的, 依法追究有关单位和 人员的责任。

\section{4 雷电灾害风险识别与风险管理措施的}

重点

\section{1 明确雷电灾害风险管理主体, 建立风 险协调和沟通机制}

明确企业或相关单位为雷电灾害风险 管理责任主体, 地方政府为风险监管和协调 主体。通过立法等手段建立雷电灾害风险沟 通协调机制, 企业或相关单位对其形成的风 险管理内容负责, 政府对企业或相关单位所 报告的风险管理内容负监管、协调和沟通责 任。

就企业或相关单位而言, 要进一步强化 企业或相关单位负责人（法定代表人）的风 险管理责任。企业或相关单位负责人应负责 组织雷电灾害风险评估工作, 提出并采取雷
电灾害风险控制措施, 组织进行雷电灾害风 险登记和风险排查。另外, 企业或相关单位 要明确员工的风险管理职责: 一是通过培训 等方式, 让员工能够明白自己工作中可能遇 到的风险和受到的伤害, 并且应当严格遵守 各项工作安全措施; 二是对于在风险防控工 作中遇到的缺陷, 减少风险的方法等, 员工 负有根据既定制度告知相关负责人的义务。

就政府主体而言, 根据《中华人民共和 国突发事件应对法》，应急管理适用属地管 理原则, 建议明确负有安全生产监督管理职 责的部门为事故灾难风险管理监管主体, 监 督管理部门所在地政府为风险管理协调主 体。先由负有安全生产监督管理职责的部门 派人参加风险评估小组并督促企业完成风 险评估报告, 再由该部门负责审核通过后报 本级政府, 并定期复审、督促修订。监督管 理部门所在地政府根据风险评估报告承担 相关的协调责任, 明确与之相关的风险管理 各主体职责并予以协调, 如企业提出的雷电 灾害风险控制措施超出了本级政府的协调 能力, 可以上报上一级政府及其部门继续予 以协调。同时, 负有安全生产监督管理职责 的部门对雷电灾害风险利益相关者应当负 有风险沟通的义务。

\section{2 理顺雷电灾害事故突发事件风险管理 的流程}

\section{2.1 雷电灾害风险管理准备}

雷电灾害事故突发事件风险管理准备 首要是成立风险评估小组。雷电灾害风险评 估小组成员应当由企业人员和政府相关部 门人员组成。由于雷电灾害应急预案编制与 管理是应急管理的重点, 故建议可将企业应 急预案编制小组并入风险评估小组。要确定 风险评估小组职能: 明晰雷电灾害风险管理 工作流程; 分别确定管理流程中的企业责任 和政府责任。

\section{2.2 雷电灾害风险识别}

根据我国相关法律法规, 企业是风险识 别的主体。企业可借鉴国内外的先进做法, 结合雷电灾害事故突发事件风险管理实际, 负责以下工作。一是排查识别雷电灾害危险 源。根据事先所确定的企业危险源清单 (物 
理、化学、力学、电学、生物等), 查找所 有可能的雷电灾害危险源, 确定危险源及其 可能的影响范围; 二是分析雷电灾害危险源 产生的原因, 可能导致的结果及其对周边环 境的影响。

\section{2.3 雷电灾害风险分析}

借鉴国内外先进的雷电灾害风险分析 方法, 利用 “发生可能性 $\times$ 后果严重性” 分 析某种雷电灾害危险源的风险水平。由于企 业熟悉自己的雷电灾害危险源和生产经营 特点, 雷电灾害风险分析应当由企业完成。 雷电灾害风险分析更侧重技术层面分析, 再 加之各个企业特点和雷电灾害危险源的不 同, 在此不作为重点探讨。

\section{2.4 雷电灾害风险处置}

雷电灾害风险处置也是雷电灾害风险 控制的主要内容, 具体到雷电灾害事故突发 事件风险管理中, 是对雷电灾害风险源隐患 治理。政府相关部门对企业的风险处置情况 进行监督管理, 已经有了一些切实有效的监 督管理办法。比如, 实行雷电灾害事故隐患 排查治理报告制、雷电灾害事故隐患整改承 诺制、公示制等。企业可以以前期雷电灾害 风险识别和分析得到的雷电灾害风险等级 为依据, 与政府相关部门进行雷电灾害风险 沟通后, 提出具体、实用的雷电灾害风险处 置措施。

\section{2.5 雷电灾害风险管理的沟通协调}

在雷电灾害事故突发事件风险管理 中, 企业、政府都应负有风险管理沟通的 任务。企业应当将雷电灾害风险评估结果、 处置措施、利益相关者等雷电灾害风险管 理信息报给负有安全生产监督管理职责的 部门和有关行业主管部门, 再由其通知利 益相关者。

\section{3 雷电灾害事故突发事件风险管理重点}

雷电灾害事故突发事件风险管理重点 是雷电灾害风险源的识别及对周边环境的 影响评估。如果雷电灾害风险源相同, 但由 于周边环境不同, 雷电灾害风险等级必然不 同, 发生事故后所造成的损失也不同。比如, 一个炸药库肯定是危险的, 如果将这个炸药 库建在荒无人烟的地方, 一旦爆炸, 对人的
生命和财产安全危害相对较小, 其雷电灾害 风险等级较低。相反, 如果炸药库设在市区 或周围有重要设施的地方, 则雷电灾害风险 等级高。目前许多企业十分缺乏对超出企业 内部处置能力的雷电灾害风险源的影响评 估, 相关部门也缺乏对此种影响评估的监督 管理, 更欠缺针对某一雷电灾害风险源与相 关部门的协调和沟通。

因此, 企业应当进行雷电灾害风险源对 周边环境的影响评估, 识别出次生灾害区域 及雷电灾害风险等级, 其具体的评估步骤如 下：一是识别确定雷电灾害风险源, 并明确 雷电灾害风险源的自身特点; 二是根据雷电 灾害风险源的自身特点, 确定评估领域范 围, 如生态、能源、经济等领域; 三是在领 域范围内, 找到对应雷电灾害风险源对周边 环境的影响; 四是提出采取防控雷电灾害风 险源隐患及其对周边环境的影响等雷电灾 害风险控制措施。企业应将超出其内部处置 能力的雷电灾害风险源影响区域评估以书 面形式提交政府安全监督管理部门, 由其根 据企业提交的排查结果报本级政府, 由本级 政府与其他相关部门等进行沟通、协调, 共 同形成雷电灾害风险源环境影响评估报告。

\section{4 发挥雷电灾害应急预案体系整体作} 用, 实现政企预案有效联动

在单项雷电灾害应急预案 (含企业预案 和政府预案) 编制和评审中, 应重点开展以 下几方面工作。一是为增强预案的科学性、 针对性, 要根据企业预案和政府预案的不同 特点, 分别规定雷电灾害风险评估的流程、 内容、重点; 二是建立雷电灾害事故突发事 件应急预案体系启动机制, 实现政府和企业 预案有效联动。该机制可遵循由生产经营单 位到政府, 由微观现场处置到宏观政府组织 协调, 预案体系全面、无缝隙启动的思路。

\section{5 结语}

雷电灾害风险管理是一项复杂的系统, 它既是理论问题, 更是实践问题。雷电灾害 虽然具有突发性, 但也是可以预防的, 雷电 灾害固然具有较大的破坏性, 会给人们带来 经济损失、人员伤亡等灾难, 但从发展的角 度来看, 每次灾难性雷电灾害事故背后也会 给社会带来巨大的进步。雷电灾害既给人类 
带来危害, 同时也昭示着机会, 从雷电灾害 风险管理的意义上来说, 每一次雷电灾害突 发事件的出现, 常常可以发现雷电安全保障 中存在的问题, 并对当前雷电灾害风险管理 的不足进行剖析和反思, 最后在现有的防雷 减灾对策的基础上, 依据雷电灾害管理相关 理论并结合雷电灾害的特殊情况, 提出完善 的雷电灾害风险管理体系的对策思路, 使雷 电灾害风险管理走向法治化和程序化道路。

\section{参考文献}

[1] 李家启, 李良福. 雷电灾害风险评估与 控制. 北京: 气象出版社, 2010 .

[2] 马明, 吕伟涛, 张义军, 孟青. 我国雷电 灾害及相关因素分析. 地球科学进展, 2008, (8): 856-865.

[3] 繆旭明. 加强气象应急管理工作提高防 灾抗灾减灾效能. 气象软科学, 2008(1).

[4] 杜小松. 气象灾害服务后的思考. 气 象软科学, 2008(4). 